\title{
El movimiento obrero cubano durante la Guerra de los Diez Años (1868-1878)*
}

\author{
Joan Casanovas Codina
}

Universitat Rovira i Virgili. Tarragona

El presente ensayo analiza un tema poco estudiado: las luchas de los trabajadores urbanos en Cuba durante la Guerra de los Diez Años (1868-1878). Varios autores -Aguirre, Hidalgo, Plasencia - dan a entender que no existió un vínculo entre los orígenes del movimiento obrero cubano en la década de 1860 y las importantes movilizaciones obreras de la década de 1880. Sin embargo, un estudio detallado del período de la guerra muestra que el artesanado de la isla consiguió seguir luchando colectivamente en defensa de sus intereses, lo cual es fundamental para comprender el espectacular crecimiento del movimiento obrero al finalizar la Guerra de los Diez Años en 1878.

El intento de España por modificar su política hacia Cuba en la década de 1860, creó un marco político favorable para que el movimiento obrero diese sus primeros signos de vida y se convirtiese en una fuerza importante en la transformación de la sociedad colonial y esclavista cubana. ${ }^{1}$ En su colaboración con el reformismo criollo que surgió a inicios de esta década, el movimiento obrero descubrió nuevas formas para mejorar las condiciones de trabajo y de vida de las clases populares. El éxito del movimiento obrero reformista a la hora de establecer la lectura en los talleres de tabaquería, y de movilizar a personas de origen y color diferente, reforzó esta línea de acción. Sin embargo, esta ola de activismo obrero fue muy breve puesto que ya desde mediados de 1866 la administración colonial emprendió una campaña represiva contra él. Un año después, la represión gubernamental se intensificaría aún más. ${ }^{2}$

Al estallar la Guerra de los Diez Años en 1868, el entonces capitán general, Francisco Lersundi, movilizó a las pocas tropas regulares con capacidad de combatir (unos ocho mil soldados de los 22.000 que tenía el

* Una primera versión de este artículo fue presentada en el XI Congreso Internacional de AHILA, Liverpool 17-22 de septiembre de 1996.

1 Véase por ejemplo Aguirre, Sergio: Eco de caminos. La Habana, 1974; Hidalgo, Ariel: Orígenes del movimiento obrero y del pensamiento socialista en Cuba. La Habana, 1976; Plasencia Moro, Aleida: "Historia del movimiento obrero en Cuba", en Pablo González Casanova, ed.: Historia del movimiento obrero en América Latina. México, 1984, T. 1, págs. 88-183; e Instituto de Historia [...] de Cuba: Historia del movimiento obrero cubano, 1865-1958, 2 vols., La Habana, 1987.

2 Sobre este proceso histórico, véase Casanovas, Joan: "The Cuban Labor Movement of the 1860s and Spain's Search for a New Colonial Policy”, Cuban Studies, 25, Pittsburg. Pa., 1995, págs. 83-99. 
ejército regular en Cuba), para que acabaran con el levantamiento en la región oriental de la isla, y rearmó a los batallones de voluntarios (una milicia irregular) para proteger las ciudades de toda la isla y la economía de plantación de las regiones occidental y central. Hasta el final de la guerra, éste fue el destino militar de la mayoría de voluntarios. ${ }^{3}$ Por su parte, durante varios años el gobierno metropolitano no pudo enviar refuerzos debido a las insurrecciones carlistas y republicanas en la península.

Alarmado por los sucesos, el gobierno metropolitano trató de apaciguar a los separatistas cubanos con la promesa de que, tan pronto depusiesen las armas, se introducirían importantes reformas políticas en Cuba. No obstante, el reaccionario general Lersundi se negó absolutamente a modificar su forma de gobernar y recurrió al ala más integrista del partido español ("los buenos españoles") para impedir cualquier negociación con los separatistas, y aun la mera posibilidad de que se reformara la política colonial. ${ }^{4}$ Con el apoyo y la ayuda financiera del partido español, en sólo tres meses Lersundi incrementó el cuerpo de Voluntarios de 10.000 a 35.000 soldados, de los cuales 9.000 se concentraban en La Habana. Al igual que cuando se constituyó esta milicia en 1855, la oficialidad del cuerpo quedó en manos de los peninsulares, que obligaron a sus empleados o a los tenderos subordinados a ellos a través de las redes comerciales y los círculos sociales, a alistarse masivamente, de manera que la tropa de este cuerpo armado pasó a estar compuesta casi exclusivamente por tenderos, cocheros, carretoneros, dependientes y artesanos, todos ellos de origen peninsular. ${ }^{5} \mathrm{~A}$ diferencia de las tropas regulares, los Voluntarios guardaban su fusil en casa y lo

3 El Instituto de Voluntarios de Cuba no debe confundirse con los batallones de mercenarios enviados desde la península por las distintas burguesías metropolitanas desde comienzos de 1869 con nombres tales como Voluntarios Catalanes, Chapelgorris, etc., y que se ocuparían principalmente de vigilar las haciendas y de combatir en el frente. Sobre los Chapelgorris en Matanzas, véase Bergad, Laird W.: Cuban Rural Society: the Social and Economic History of Monoculture in Matanzas, Princeton, 1990, pág. 184. Sobre los Voluntarios Catalanes, véase Moreno Masó, Joaquín José: La petjada dels catalans a Cuba, Barcelona, 1992.

4 Guerra, Ramiro: La Guerra de los 10 Años, La Habana, 1972, vol. 1, págs. 184-187. Jiménez Castellanos, Adolfo: Sistema para combatir las insurrecciones en Cuba, Madrid, 1883, pág. 13. Sedano y Cruzat, Carlos de: Cuba: Estudios políticos, Madrid, 1872, pág. 365.

5 Véase Zaragoza, Justo: Las insurrecciones en Cuba, Madrid, 1872-1873, vol. 2, págs. 249-251; Otero y Pimentel, Luis: Memoria sobre los voluntarios de la isla de Cuba, La Habana, 1876, págs. 49-50; Balmaseda, Francisco Javier: Los confinados a Fernando Póo e impresiones de un viage a Guinea, Nueva York, 1869 [i.e. 1870?], pág. 34; Sedano: Cuba: Estudios..., pág. 365; Pardo Pimentel, Nicolás: La isla de Cuba: su prosperidad o su ruina, Madrid, 1870, pág. 13; Ochando, Federico: El General Martínez Campos, Madrid, 1878, pág. 155; Guerra: La Guerra..., vol. 1, págs. 192-194; y Moreno Fraginals, Manuel, y Moreno Masó, José J.: Guerra, migración y muerte, Asturias, 1993, págs. 95-98. 
llevaban consigo cuando salían a la calle, permitiéndoles imponer su voluntad por la fuerza a cualquier persona sospechosa de ser reformista o separatista ${ }^{6}$ Los batallones de Voluntarios pronto tendrían un órgano de prensa diario, La Voz de Cuba, dirigido por Gonzalo Castañón, un abogado peninsular que utilizaba un lenguaje violentamente anti-criollo y racista, haciendo gala del más puro integrismo.

Para superar el obstruccionismo de Lersundi a la introducción de reformas políticas en Cuba, a finales de 1868 los nuevos gobernantes metropolitanos (los generales Francisco Serrano y Juan Prim) ordenaron que lo sustituyera el general Domingo Dulce, uno de los líderes de la revolución de 1868 en España y ex-gobernador de Cuba durante el período reformista. Ya en Cuba, Dulce intentó llegar a un entendimiento con los reformistas, así como negociar la paz con los separatistas alzados en armas en Oriente, sobre la base de una amplia reforma de las leyes coloniales. Para mostrar su buena voluntad, permitió que la prensa tratara libremente cualquier tema excepto la abolición de la esclavitud y el separatismo cubano, suprimió las comisiones militares establecidas por Lersundi, amnistió a los prisioneros políticos y dio cuarenta días a los separatistas para presentarse a las autoridades sin que se formase causa alguna contra ellos. Con su política Dulce no consiguió apaciguar a los separatistas, pero en cambio se ganó la absoluta enemistad del partido español.

Los sucesos de enero de 1869 ponen de relieve que el separatismo era popular entre muchos criollos de la región habanera, la más urbanizada de Cuba, a la vez que muestran la fuerte división existente entre las clases populares. Poco antes de la llegada de Dulce ya habían tenido lugar algunas manifestaciones separatistas. Por ejemplo, el 30 de diciembre de 1868 una multitud de 9.000 personas asistió en La Habana al entierro de un joven separatista llamado Camilo Cepeda. El cortejo fúnebre tuvo que hacer frente a la oposición de la Iglesia y de la administración colonial para poder enterrarlo cristianamente. ${ }^{7}$ El 6 de enero, dos días después de la llegada de Dulce, el funeral del popular simpatizante del separatismo Tirso Vázquez, al que un militar español había matado por no cederle el paso en una vereda, convocó a una multitud de 5.000 personas que intentaron llevar el ataúd a hombros por toda La Habana. Cuando las fuerzas del orden se lo impidieron, los asistentes prorrumpieron en vivas al separatismo y se enfrenta-

6 Piñeyro, Enrique José M.: Morales Lemus y la revolución de Cuba, Nueva York, 1871, pág. 71. Guerra: La Guerra..., vol. 1, págs. 193-194.

7 Le Riverend, Julio: La Habana (Biografía de una provincia), La Habana, 1960, pág. 392. 
ron a ellas. En las dos semanas siguientes, en la capital y las poblaciones cercanas tuvieron lugar varias escaramuzas entre algunos separatistas y las fuerzas armadas españolas, que se saldaron con varios muertos por ambas partes. Algunas mujeres, conocidas como "ángeles", participaron en las manifestaciones separatistas vestidas con los colores de la bandera cubana salpicados de estrellas blancas. Por último, la efímera libertad de prensa concedida por Dulce en enero de 1869 permitió que súbitamente surgieran más de cincuenta periódicos en quince días, varios de los cuales hicieron propaganda separatista sin transgredir formalmente la ley de prensa. ${ }^{8}$

En medio de esta tensa atmósfera, el 22 de enero Dulce anunció que Cuba elegiría dieciséis diputados para que representaran a Cuba en las cortes de Madrid. La reacción del partido español no se hizo esperar. Inmediatamente desató una ola de violencia que le dio el control efectivo de La Habana y de la mayoría de las poblaciones grandes de la isla, con lo que cualquier esperanza de una solución negociada a la guerra, como la propuesta por Dulce, quedó destruida. La representación de una obra cómica en el teatro Villanueva de La Habana fue el detonante. Al saber que los separatistas utilizaban el evento para hacer propaganda y recaudar fondos para la revolución, varios voluntarios asaltaron el local e intercambiaron disparos con miembros del público, mayoritariamente compuesto por tabaqueros y artesanos con sus familias.

Después del asalto al Villanueva hubo tiroteos en varios barrios de La Habana. El café El Louvre fue escenario de un enfrentamiento particularmente sangriento. Tras cuatro días de violencia en las calles, el balance fue de entre quince y treinta muertos. Una vez consiguieron controlar la ciudad, los voluntarios empezaron a hostigar y a detener a los líderes reformistas o a cualquier persona sospechosa de apoyar a los separatistas; simultáneamente, en otras poblaciones de la isla llevaron a cabo acciones parecidas. ${ }^{9}$ Por

8 Sobre estos sucesos, véase García del Pino, César: "La Habana en los días de Yara", RBNJM, 20, La Habana, 1878, págs. 158-168; y Zaragoza, Las insurrecciones..., vol. 2, págs. 268-269. Un listado bastante completo de estos periódicos se encuentra en Labraña, José M.: "La prensa en Cuba”, en Esteban Roldán Oliarte, ed.: Cuba en la mano, La Habana, 1940, págs. 649-786.

9 Sobre la ola de violencia que se desencadenó a raíz del asalto al teatro Villanueva, véase Sedano: Cuba: Estudios..., pág. 380; Zaragoza: Las insurrecciones..., vol. 2, págs. 277-282, 308; Le Roy, Luis Felipe: A cien años del 71: el fusilamiento de los estudiantes, La Habana, 1971, págs. 25-53; Robreño, Joaquín: "Los sucesos del teatro Villanueva", Boletín del Archivo Nacional de Cuba (en adelante “BANC”) 40, La Habana, 1941, págs. 135-150; Guerra: La Guerra..., vol. 1, págs. 138-139, 157-158; y García del Pino: "La Habana...", págs. 167-172. Sobre el fracaso de introducir elecciones en Cuba a comienzos de la guerra, véase Roldán, Inés: "El fracaso de las reformas en Cuba: la cuestión electoral (1869-1872)", en Consuelo Naranjo y Tomás Mallo, eds.: Cuba, la perla de las Antillas, Aranjuez, 1994, págs. 223-237. 
último, dado que la mayoría de los liceos y las sociedades filarmónicas habían sido centros reformistas a lo largo de la década de 1860, e incluso algunas de estas sociedades habían servido como centros de conspiración separatista, la administración española en la isla ordenó su cierre.

Con el partido español dictando la política en Cuba, el capitán general se vio forzado a suprimir todas las libertades que había concedido a su llegada a la isla, y a aplicar severos castigos a todo individuo sospechoso de estar involucrado en actividades subversivas. Entre otras medidas, Dulce prohibió "la coalición de jornaleros", ${ }^{10}$ con lo que los trabajadores perdieron toda esperanza de reconstruir a corto plazo el movimiento obrero suprimido por Lersundi. A raíz de estas disposiciones comenzó una ola de arrestos y encarcelamientos en la que los voluntarios actuaron por su cuenta, sin atender al orden legal. Al cabo de dos meses Dulce había deportado gubernativamente (es decir, sin juicio previo) a 250 prisioneros a Fernando Poo (Bioko). La mayoría eran criollos acaudalados o de profesiones liberales; pero entre los deportados también había algunos artesanos y campesinos, así como unos cuantos peninsulares. ${ }^{11}$ Hasta el fin de la guerra la administración colonial deportó, como mínimo, a 1.400 personas (58 \% de ellos a la isla de Pinos, $21 \%$ a Fernando Poo, 17 \% a España, y el resto a los enclaves españoles en el norte de África)..$^{12}$ De la misma manera, Dulce aceptó la brutal táctica de guerra del general Blas Villate (conde de Valmaseda) en Oriente, basada en la guerra a muerte y la reconcentración de todos los habitantes en poblaciones con guarnición.

En los meses siguientes, casi todos los peninsulares adultos que aún no pertenecían a los voluntarios fueron obligados a alistarse al cuerpo. Por ejemplo, poco después del asalto al café El Louvre, su propietario, el catalán Joaquín Payret, formó una compañía con el apoyo de todos los comerciantes de la calle donde se encontraba dicho café, integrada por todos los dependientes de cada uno de sus establecimientos. Tal como el mismo Payret declaró: "Nos hemos hecho voluntarios para defendernos de

10 Zaragoza: Las insurrecciones..., vol. 2, págs. 310, 752.

11 Saluvet, Juan B.: Los deportados a Fernando Poo en 1869, Matanzas, 1892; Balmaseda: Los confinados...

12 Porcentajes calculados a partir de datos proporcionados por M. ${ }^{a}$ Dolores Domingo Acebrón: "Los deportados de la Guerra de los Diez Años: Cuba (1868-1878)", Revista de Indias, T. 51, núm. 191, Madrid, 1991, págs. 156-162. Es muy probable que el número de deportados fuera bastante superior a 1.400. Sólo en Isla de Pinos, en 1875, había 884 deportados políticos y 358 por vagancia. Véase Julián Ajo Jacques: "Memoria histórica [...] de la Isla de Pinos [...] escrita en el año de 1875", BANC, 12, La Habana, 1913, págs. 286-317. 
"nosotros mismos"". ${ }^{13}$ A menudo los peninsulares de clase trabajadora se alistaron a ese cuerpo para evitar ser reclutados por el ejército regular y enviados al frente, o ser enjuiciados por no haberse presentado a filas en la península. En pocos meses, el número de voluntarios ascendió a 70.000, de los cuales 15.000 estaban en La Habana. En el caso de Saturnino Martínez, un destacado líder obrero desde mediados de la década de 1860, probablemente se alistó, no sólo por sus convicciones nacionalistas, sino, sobre todo, para evitar sospechas por su proximidad al reformismo criollo antes de la guerra. Como voluntario, Martínez alcanzó el rango de teniente segundo, e incluso dedicó algunos de sus pésimos poemas al Instituto. ${ }^{14}$

La violencia desencadenada por los voluntarios obligó a miles de personas —en su mayoría de origen criollo - a huir de la isla. Los criollos no estaban sujetos a las quintas, lo que facilitó su salida de la isla. En los cinco días siguientes a los sucesos del teatro Villanueva y El Louvre, 300 familias solicitaron autorización para salir de Cuba. En los seis meses siguientes probablemente se exiliaron alrededor de 20.000 personas. Durante la guerra, muchas más lo hicieron para escapar de la represión política y la inestabilidad económica. ${ }^{15}$ Fueron tantas las personas que se marcharon, que pese a la llegada de gran número de inmigrantes españoles durante toda la década de 1870, la población de La Habana quedó estancada en unos doscientos mil habitantes.

Los emigrados más adinerados se establecieron en Nueva York, París, y en varias ciudades de América Latina y el Caribe; algunos hacendados reformistas se afincaron en Madrid, donde publicaron algunos periódicos. Por su parte, los trabajadores cubanos se encaminaron principalmente a la isla de Cayo Hueso (en inglés Key West, una isla del sur de La Florida cercana a Cuba), pero también a Nueva York, Nueva Orleans y otras poblaciones estadounidenses en las que había manufacturas de tabacos, o donde

13 Robreño: "Los sucesos...", págs. 135-150.

14 Sobre Martínez, véase Archivo Histórico Nacional de Madrid, en adelante AHN, Ultramar, 5899, expediente sobre el "Instituto de Artesanos"; y Friera, Florencio: "Historia de un emigrante a Cuba: Saturnino Martínez (1837-1905)”, Boletín del Instituto de Estudios Asturianos, 43, Oviedo, 1989, pág. 222.

15 Los libros que tratan este tema ofrecen cifras de emigrados muy dispares. Según Justo Zaragoza (Las insurrecciones..., vol. 2, págs. 374 y 774), unas cien mil personas salieron de la isla en estos seis meses (citado por Guerra y Sánchez: La Guerra..., vol. 1, pág. 163, n. 1). Portell Vilá, Herminio (Historia de Cuba en sus relaciones con los Estados Unidos y España, Miami, 1969, vol. 2, pág. 227) menciona que pudieron ser más de treinta mil los exiliados. Tomando en cuenta que la mayoría de emigrados se dirigieron a EE.UU., donde a mediados de la década de 1870 había más de doce mil cubanos, es razonable pensar que en esta época se exiliaran como máximo unas veinte mil personas con destino a varios países. 
empresarios cubanos, españoles o americanos las estuvieran construyendo. A mediados de la década de 1870 había al menos 12.000 cubanos solamente en Estados Unidos. ${ }^{16}$ Según los propios fabricantes de tabacos de La Habana — casi todos ellos de origen peninsular_-, a raíz de la guerra salieron "de la isla de Cuba sobre catorce mil operarios torcedores de cigarros puros y de papel" que se establecieron en los Estados Unidos, ${ }^{17}$ lo que confirma que muchos artesanos criollos eran partidarios del separatismo. ${ }^{18}$

Antes de la guerra Cayo Hueso era una pequeña población; pero en 1870 ya tenía 5.657 habitantes, y en 1876 unos doce mil, la mayoría de los cuales eran cubanos. ${ }^{19}$ Entre estos primeros exilados había líderes del movimiento obrero de mediados de la década de 1860 que se habían decantado por el separatismo, como el intelectual criollo y editor de prensa obrera Juan María Reyes. Una vez en el Cayo, Reyes fundó el semanario El Republicano, y fue uno de los principales promotores de un importante centro cultural de la comunidad cubana cayohuesera. ${ }^{20}$ Otros líderes obreros criollos permanecieron en la isla. Éste es el caso de José de Jesús Márquez, que en 1870 fue arrestado y deportado a la Isla de Pinos acusado de estar en contacto con los separatistas. ${ }^{21}$

A pesar de la represión gubernamental y de la violencia de los voluntarios, los independentistas, muchos de ellos tabaqueros, continuaron ope-

16 Véase Álvarez Estévez, Rolando: La emigración cubana en Estados Unidos 1868-1878, La Habana, 1986, pág. 97; y Poyo, Gerald: “With All, and for the Good of All”: The Emergence of Popular Nationalism in the Cuban Communities of the United States, 1848-1898, Durham, 1989, págs. 42-43. Sobre la emigración cubana en Jamaica, véase Stubbs, Jean: "Political Idealism and Commodity Production: Cuban Tobacco in Jamaica, 1870-1930”, Cuban Studies, 25, Pittsburg, 1995, págs. 51-82.

17 Gremio de la Industria del Tabaco: Exposición al Intendente de la Real Hacienda de La Habana, La Habana, 1872, vol. 1. Sobre la emigración cubana en EE.UU., además de las fuentes anteriormente citadas, véase Pérez, Louis A., Jr.: Cuba between Empires, 1878-1902, Pittsburgh, 1982, págs. 96-97; y Abad, Diana: “Las emigraciones cubanas en la Guerra de los Diez Años”, Santiago, 53, Santiago de Cuba, 1984, págs. 143-184.

18 Esta circunstancia queda perfectamente reflejada en el estudio que Tadeusz Lepkowski ha realizado de las listas de sospechosos de apoyar a los insurrectos en Guanabacoa y en Cárdenas que la administración española elaboró en 1869, "Cuba 1869: desafectos al gobierno e insurrectos", Estudios Latinoamericanos, 9, Varsovia, 1982-1984, págs. 134-37.

19 Sobre Cayo Hueso, véase Poyo, Gerald E.: "Key West and the Cuban Ten Years War", Florida Historical Quarterly, 57, Gainesville, 1978-1979, págs. 289-291; del mismo autor, "Cuban Revolutionaries and Monroe County Reconstruction Politics, 1868-1876", Florida Historical Quarterly, 55, Gainesville, 1976-1977, págs. 407-409; y Castellanos, Gerardo: Motivos de Cayo Hueso, La Habana, 1935, págs. 183-184, 197-209.

20 Sobre Reyes, véase Portuondo, José A.: “La Aurora” y los comienzos de la prensa obrera en Cuba, La Habana, 1961, págs. 75-85; Poyo: "Key West...”, pág. 292; y AHN, Ultramar, 4365-1, exp. 25 sobre el caso Reyes.

21 Instituto de Literatura y Lingüística... de Cuba, Diccionario de la literatura cubana, La Habana, 1980-1985, vol. 2, pág. 558. 
rando en La Habana y sus alrededores. El 9 de abril, durante la ejecución de dos implicados en los hechos del teatro Villanueva, se reunió una gran multitud que manifestó su apoyo a los reos y al levantamiento separatista. La respuesta de los voluntarios fue disparar indiscriminadamente contra los manifestantes causando siete muertes. ${ }^{22}$ Las actividades de aquéllos sirvieron al partido español para conseguir sus principales objetivos. Poco después de este suceso, Dulce ordenó que se embargasen las propiedades de personas sospechosas de estar en contacto con los independentistas, pero de nuevo los voluntarios tomaron la ley en sus manos arrestando y embargando a quien quisieron sin atender a los procedimientos judiciales. Desde entonces hasta finales de la guerra, se embargaron las propiedades de unas cuatro mil quinientas personas. ${ }^{23}$

Los voluntarios, guiados por el partido español, llegaron incluso a derrocar al capitán general Dulce. Pese a que desde febrero de 1869 éste había accedido a todas las exigencias del partido español, su pasado reformista no era del agrado de los partidarios del statu quo, por lo que a mediados de mayo los "buenos españoles" lanzaron una campaña en su contra. A partir de entonces el acoso a Dulce y sus colaboradores fue aumentando hasta que en la noche del 1 de junio, los voluntarios armados se concentraron en la Plaza de Armas, contando con el apoyo de algunos oficiales del ejército regular, obligaron a Dulce a renunciar al cargo y a entregarlo a otro general más afín a los deseos del partido español; lo mismo ocurrió en otras poblaciones de Cuba, donde depusieron a varios oficiales leales al capitán general. Pese a la gravedad de esta insubordinación, el gobierno de Madrid no quiso desafiar al partido español y nombró a un nuevo capitán general, Antonio Caballero de Rodas, quien se adaptó perfectamente a la voluntad de los "buenos españoles". ${ }^{24}$

\section{El nuevo partido español}

La ampliación de la base del partido español con el alistamiento de la mayoría de peninsulares al cuerpo de voluntarios provocó cambios muy significativos en las asociaciones peninsulares en Cuba. Antes de que

22 Guerra: La Guerra..., vol. 1, pág. 161. Le Riverend, La Habana..., págs. 392-396. García del Pino: "La Habana...”, págs. 162-165.

23 Roldán, Inés: La hacienda en Cuba durante la Guerra de los 10 Años (1868-1880), Madrid, 1990, págs. 69-72.

24 Guerra: La Guerra..., págs. 224-231, 329 y 333. Sedano: Cuba: Estudios..., págs. 395-413. 
Caballero de Rodas tomara posesión del cargo, los dirigentes del partido español fundaron el Casino Español de La Habana, a través del cual intentaron mantener la cohesión, dirigir la acción y proteger los intereses de todos los "buenos españoles" en Cuba. Dado que sus salones estaban abiertos tanto a la elite peninsular como a los pequeños comerciantes y a los trabajadores de ese origen, el partido español sostenía que el Casino, al igual que el Instituto de Voluntarios, era una entidad modélica porque agrupaba a personas de todos los niveles sociales. ${ }^{25}$ No obstante, eran los peninsulares más ricos, principalmente los comerciantes, los que controlaban el Casino y lo utilizaban como plataforma para proteger sus intereses políticos y económicos. Por su parte, los grandes fabricantes de tabacos (marquistas), aprovechando su condición de miembros destacados del partido español y de oficiales del cuerpo de voluntarios, hicieron realidad uno de sus viejos sueños al fundar, en 1871, una organización empresarial llamada Gremio Central del Tabaco de La Habana para defender los suyos. ${ }^{26}$

Después del establecimiento del Casino Español de La Habana, los "buenos españoles" de toda la isla fundaron centros similares en muchas otras poblaciones, algunos de los cuales continuaron existiendo hasta bien entrado el siglo XX ${ }^{27} \mathrm{~A}$ menudo los casinos españoles se establecieron en los locales de los liceos, las sociedades filarmónicas y las sociedades de ayuda mutua que habían sido clausurados al empezar la guerra. Pese a ser centros dirigidos por peninsulares, muchos criollos también participaban en sus actividades. Los círculos españoles, por tanto, no representaron una ruptura absoluta con las sociedades de recreo de antes de la guerra, y muchos de ellos continuaron ofreciendo servicios educativos y de ayuda mutua para los asociados y sus hijos. Por otro lado, los sectores burgueses metropolitanos más interesados en que se mantuviese el statu quo colonial en Cuba, fundaron una red de organizaciones llamadas centros hispanoultramarinos..$^{28}$ Desde el Casino Español de La Habana, y apoyándose tan-

25 Véase Zaragoza: Las insurrecciones..., vol. 2, págs. 434-436; y Guerra: La Guerra..., vol. 1, págs. 327-330.

26 Un par de folletos publicados en 1871 y 1872 demuestran la existencia de esta asociación: [Gremio Central] [Informe], y Gremio de la Industria: Exposición al Intendente...

27 Sobre la fundación de los Casinos Españoles y su papel en la política cubana, véase Franco, Luciano: La reacción española contra la libertad, La Habana, 1988, págs. 68-79. Además del Casino Español de La Habana, he localizado 30 casinos más en poblaciones situadas a lo largo de toda la isla y fundados entre 1869 y 1875 . La mayoría de expedientes de estos casinos se encuentran en AHN, Ultramar, 5897, 5898 y 5899.

28 Véase Justiz, Tomás: Los centros hispano-ultramarinos, La Habana, 1943, y Maluquer de Motes, Jordi: “Abolicionisme i esclavisme a Espanya”, L’Avenç, 101, Barcelona, 1987, pág. 44. 
to en la red de casinos españoles de toda la isla como en los centros hispano-ultramarinos en la metrópoli, la elite peninsular gobernó de facto el territorio hasta la proclamación de la Primera República en 1873.

La inmigración de miles de españoles, ya fuesen civiles o militares, durante toda la guerra, también propició la fundación de sociedades regionales peninsulares. En este período, gallegos, catalanes, baleáricos, valencianos, asturianos, montañeses, vascos (incluyendo a los navarros), castellanos, murcianos, andaluces y canarios fundaron asociaciones de ayuda mutua o centros culturales a lo largo de toda la isla. De ellas, la gallega y la asturiana adquirieron pronto gran tamaño e influencia, reflejando así que desde hacía algunos años la mayoría de los inmigrantes peninsulares procedía de Galicia y Asturias.

\section{Los primeros pasos del movimiento obrero durante la guerra}

La guerra produjo el colapso temporal del movimiento obrero así como la creciente militarización de las relaciones laborales en gran número de industrias y talleres. Muchos patronos, entre ellos casi todos los marquistas, adquirieron rango de oficiales del cuerpo de voluntarios. Los capataces de las fábricas y los talleres, por lo general peninsulares, se alistaron a esta milicia irregular como oficiales de baja graduación. La gran mayoría de trabajadores peninsulares se convirtieron en soldados rasos de este cuerpo armado, con lo que al menos parte de la fuerza laboral retuvo cierta capacidad de negociación ante la patronal y la administración. Durante estos años vemos como esos trabajadores solicitaban sistemáticamente a la administración que sus servicios de armas fuesen recompensados permitiéndoles establecer asociaciones populares, las cuales adoptaban nombres que expresaban apoyo al dominio español en Cuba. Por ejemplo, en 1870, algunos artesanos habaneros fundaron la Sociedad el Recreo Español; y en Cienfuegos un grupo de inmigrantes catalanes fundó el Casino Español de Artesanos, que proporcionaba servicios de recreo y educación. ${ }^{29}$

En algunos casos se fundaron asociaciones de socorros mutuos que sólo admitían a voluntarios, como La Integridad Nacional, con sede en La Habana. Una asociación artesanal que tuvo una larga vida fue la Sociedad

29 Sobre estas sociedades, véase La Unión, 12, La Habana, 17 de agosto de 1873; AHN, Ultramar, 5898; y Edo, Enrique: Memoria histórica de Cienfuegos y su jurisdicción, La Habana, 1943, pág. 570. Otra asociación fundada en estos años es el Recreo Español del Carmelo, en La Habana (véase AHN, Ultramar, 5897). 
de Socorros Mutuos Nuestra Señora del Buen Socorro, fundada en 1872 por un grupo de artesanos asturianos residentes en La Habana. Según su reglamento, el Buen Socorro sólo podía tener 100 socios, todos ellos de origen asturiano. Hasta la década de 1890 la asociación no superó este número de asociados. ${ }^{30}$

Por su condición de voluntarios y de peninsulares, en 1872 los escogedores de tabacos de La Habana pudieron establecer la Sociedad Protectora del Gremio de Escogedores, el primer sindicato de oficio de Cuba, cuyo objeto era "proteger a los trabajadores del Gremio contra las injustas exigencias de los fabricantes". ${ }^{31}$ Mientras tanto, los litógrafos y los cocheros, dos oficios en que había muchos españoles, pudieron incluso declarar algunas pequeñas huelgas durante el otoño de 1872. Ya en esta fecha vemos que la administración colonial se preocupó porque muchos de los huelguistas eran voluntarios que llevaban el fusil consigo, lo que motivó que se intercambiaran varios telegramas entre La Habana y Madrid. ${ }^{32}$

A pesar de haber conseguido algunos avances, la represión contra el movimiento obrero continuó. La administración se negó sistemáticamente a autorizar la constitución de sociedades de artesanos aunque éstos fueran miembros del cuerpo de voluntarios. Por ejemplo, en 1871 un grupo de asturianos -entre ellos Saturnino Martínez, el principal líder obrero de la década de 1860—, solicitó sin éxito fundar una sociedad de recreo. Después de dos meses de investigaciones, el secretario de orden público informó al capitán general del pasado de Martínez como líder obrero y de su actuación durante la huelga de 1867, y le comentó que consideraba peligrosa esta asociación porque la mayoría de sus miembros serían tabaqueros, "siendo de notar que no es ésta la gente más pacífica y moral de La Habana". ${ }^{33}$ Algunos meses después, en enero de 1872, el capitán general envió una circular a los gobernadores de provincia, dando instrucciones de actuar con severidad en caso de producirse huelgas. ${ }^{34}$

La administración colonial y el partido español temían que los soldados o los deportados procedentes de la península facilitaran que los traba-

30 AHN, Ultramar, 5897 y 5899.

31 Véase el reglamento de la sociedad de 1880 en la BNJM.

32 Sobre los litógrafos, véase Seco Serrano, Carlos, introducción y ed.: Colección de documentos para el estudio de los movimientos obreros en España en la época contemporánea, Barcelona, 1969-1972, vol. 2, págs. XXV-XXVII. Sobre los cocheros, véase Real Academia de la Historia (en adelante, RAH), Colección Caballero de Rodas, vol. V, docs. 980-81, f. 27; y Giralt, Pedro: Historia contemporánea de la Isla de Cuba, La Habana, 1896, pág. 31.

33 AHN, Ultramar, 5899, exp. sobre el "Instituto de Artesanos".

34 La Razón, 8:382, La Habana, 8 de diciembre de 1873, pág. 3. 
jadores en Cuba se pusiesen en contacto con los representantes de la Asociación Internacional de los Trabajadores (Primera Internacional) en la metrópoli. Con la revolución española de 1868, la Primera Internacional expandió enormemente su influencia en la península, y en el congreso obrero de Barcelona de 1870 las asociaciones de trabajadores constituyeron la Federación Regional Española (FRE), adscrita a La Internacional. En referencia a las diferencias entre marxistas y bakuninistas, desde el principio la mayoría de las organizaciones obreras de la FRE, sobre todo en Cataluña y Andalucía, se inclinaron por el bakuninismo.

A pesar del éxito que tuvo la FRE en España, es muy probable que los trabajadores de Cuba nunca consiguieran organizar una sección de la Internacional. No ha quedado registro de ninguna comunicación formal entre la FRE y los trabajadores cubanos. ${ }^{35} \mathrm{El}$ gobierno español, a la vez que lanzaba una campaña represiva en contra de la FRE, intensificó sus esfuerzos para evitar que el movimiento obrero en España se vinculara con los trabajadores de Cuba y Puerto Rico. El hecho de que la mayoría de los peninsulares que inmigraban a Cuba procediesen de Galicia o Asturias — dos regiones en las que la FRE tenía poco arraigo — ayudó a mantener el aislamiento de las organizaciones obreras cubanas. Desde comienzos de la guerra, los periódicos integristas de mayor circulación, así como varios folletos publicados en Cuba y España, expresaron alarma ante la posibilidad de que La Internacional extendiera su influencia a la isla. Con todo, la impresionante campaña de propaganda en contra de La Internacional contribuyó a difundir sus principios en aquélla. Según un artículo de Saturnino Martínez, esta campaña no sólo provocó "terror en las clases pudientes", sino también fascinación en "la mente de las masas, inclinándola en realidad a ese género de principios".

\section{El movimiento obrero de los trabajadores cubanos en Estados Unidos}

Otra de las preocupaciones del partido español y la administración colonial, tanto en Cuba como en España, era la radicalización de los tabaqueros emigrados a Estados Unidos. La libertad de que disfrutaban los obreros exilados en ese país, les permitió establecer organizaciones obreras estrechamente asociadas al ala más progresista del movimiento indepen-

35 Seco Serrano: Colección de documentos..., vol. 2, págs. XVII-XVIII. 
dentista, liderada por el general Manuel de Quesada. Los quesadistas sostenían que la república en armas debía poner fin inmediatamente a la esclavitud en Cuba y que debía atender a los intereses de las clases trabajadoras. En cambio, los seguidores de Miguel Aldama, un rico hacendado de Occidente, querían el fin del dominio español en la isla, pero sin que esto comportara cambios sociales significativos. ${ }^{36}$

Los quesadistas, con el apoyo masivo de los trabajadores tabacaleros, fundaron asociaciones para aprovisionar expediciones y proporcionar hombres a la república en armas. En Cayo Hueso los artesanos fundaron la Sociedad de los Pares, el Club Patriótico Cubano, la Asociación Cubana del Sur y la Sociedad de Instrucción y Recreo San Carlos; en Nueva Orleans la Sociedad de Artesanos de Nueva Orleans, la Sociedad Hijos del Pueblo y el Club de Artesanos; y en Nueva York la Sociedad de Artesanos de Brooklyn y la Sociedad de Artesanos Cubanos. Asimismo, muchos hombres de todos los estratos sociales del exilio ingresaron en logias masónicas, órdenes fraternales e iglesias protestantes. Entre los artesanos, la fraternidad más popular era la Orden Independiente de los Odd Fellows (IOOF) - que sigue teniendo algunas logias en la Cuba actual-, probablemente porque en Estados Unidos la mayoría de sus integrantes eran trabajadores. Asociarse a órdenes como la IOOF, permitía a los trabajadores cubanos recibir asistencia en casi todas las ciudades manufactureras estadounidenses. ${ }^{37}$

Los artesanos cubanos en el exilio, al fundar sus asociaciones, se basaron tanto en la experiencia adquirida por su participación en el movimiento obrero en Cuba antes de la guerra, como en las nuevas formas asociativas existentes en Estados Unidos. A lo largo de los diez años que duró la guerra, esta rama del movimiento obrero cubano evolucionó desconectada de las organizaciones de trabajadores en la isla. Al igual que las asociaciones de artesanos existentes en Cuba antes de la guerra, las de la emigración también proporcionaban asistencia mutua, así como escuelas para los asociados y sus familias. En algunos casos incluso llegaron a fundar cooperativas. $^{38}$

36 Sobre los aldamistas, véase Cepero Bonilla, Raúl: "Azúcar y abolición” [1. a ed. 1948], en ídem., Escritos históricos, La Habana, 1989, caps. 14-18; y el excelente ensayo de Dionisio Poey Baró: La entrada de los aldamistas en la Guerra de los Diez Años, La Habana, 1989.

37 Sobre la composición social de los IOOF entre 1872 y 1914, véase Clawson, Mary Ann: "Fraternal Orders and Class Formation in the Nineteenth-Century United States", Comparative Studies in Society and History, 1985, págs. 679-680. Véase Castellanos: Motivos..., págs. 152-153, 159-160, 243-248.

38 Castellanos: Motivos..., caps. 12 y 16. 
Por otra parte, los trabajadores cubanos en los Estados Unidos restablecieron las lecturas de libros y periódicos en las fábricas de tabacos, que habían sido prohibidas en Cuba a mediados de 1866. La lectura alcanzó tal grado de popularidad que en ciudades como Nueva York varios colectivos de trabajadores tabacaleros no cubanos adoptaron esta práctica. Según $L a$ Revolución, un periódico cubano de tendencia quesadista publicado en Nueva York, "el Gobierno español prohibió en La Habana las lecturas" para mantener a las masas ignorantes, y por esta razón "nuestros artesanos buscan hoy el modo de aprender todo lo que el despotismo quiso que desconocieran". A menudo, los líderes independentistas eran los lectores de tabaquería más populares. ${ }^{39}$

Por otra parte, a diferencia de las organizaciones de trabajadores que seguían operando en Cuba con muchas dificultades, el movimiento obrero en el exilio entró en contacto con La Internacional directamente. A finales de la década de 1860 Nueva York contaba con varias delegaciones de La Internacional. Después de que a inicios de la década de 1870 se produjera el cisma entre marxistas y bakuninistas, el Consejo General de La Internacional - de tendencia marxista - se estableció en Nueva York entre 1872 y 1876. Una carta del cónsul español en aquella ciudad enviada al ministro de estado en Madrid, muestra que los quesadistas apoyaban a La Internacional y a los comuneros de París. Según el informe del cónsul, los trabajadores tabacaleros cubanos que vivían en Nueva York y en Brooklyn, la mayoría de ellos quesadistas, se manifestaron en enero de 1872, junto a un grupo de comuneros exiliados, en contra de la ejecución de dos revolucionarios en Francia, lo cual evidenciaba, "que gran número de los insurrectos cubanos, forman parte de la sociedad 'La Internacional', particularmente los del partido llamado Quesadista, que declaran que 'la causa de la Comuna' es la causa de 'Cuba Independiente', y aceptando todos los demás principios de tan funesta Sociedad". A raíz de la creciente radicalización de los trabajadores cubanos, el cónsul informaba con satisfacción que el movimiento separatista estaba cada vez más dividido entre los aldamistas y los quesadistas; pero consideraba peligroso que los emigrados cubanos hubiesen adoptado "las disolventes doctrinas de la Internacional", lo cual ponía de manifiesto que el objetivo de los independentistas era "la destrucción de las grandes propiedades y la disolución de la Sociedad y la familia en aque-

39 “Artesanos-Conferencias”, La Revolución, 2:203, Nueva York, 4 de octubre de 1870, pág. 1. Castellanos: Motivos..., págs. 185 y 203-204. 
lla Antilla" ${ }^{40}$ Paralelamente a esta manifestación, los dos periódicos quesadistas de Nueva York, La República y La Revolución, expresaron su apoyo a la Comuna, en tanto que en Cayo Hueso, El Republicano y La Revolución incluso debatieron sobre la necesidad de adoptar las ideas socialistas. ${ }^{41}$

Entretanto, la guerra en Cuba quedaba estancada: los separatistas, a pesar de estar mal pertrechados, consiguieron desarrollar una guerra de guerrillas en el este de la isla; mientras que el ejército español pudo mantener el control de la mayoría de las poblaciones gracias a los envíos de tropas y armamento desde la península. Por otro lado, a causa de la falta de acuerdo entre los dirigentes independentistas, algunos de los cuales no estaban interesados en provocar el colapso de la economía esclavista, las fuerzas insurrectas no se atrevieron a invadir Occidente y destruir la economía de plantación..$^{42}$ Por tanto, vemos que con la construcción de una línea fortificada (llamada "trocha") en el punto más estrecho de la isla entre Júcaro y Morón (entre el Camagüey y la región central), España pudo evitar que la guerra destruyera las ricas regiones azucareras y tabacaleras del centro y el oeste del territorio. Durante este período el gobierno quedó de facto en manos del partido español, que no tuvo problema para conseguir que la administración colonial nombrara capitanes generales que se distinguieran por su integrismo.

\section{Los republicanos federales en Cuba durante la Primera República Española}

La proclamación de la Primera República Española en febrero de 1873 hizo virar de nuevo a la administración metropolitana hacia una política colonial reformista. En marzo, la abolición de la esclavitud en Puerto

40 RAH, Colección Caballero de Rodas, vol. IV, doc. 858, ff. 270-71, carta del embajador español en Washington al ministro de Estado, 27 de enero de 1872: "Manifestación de comunistas franceses y emigrados cubanos, La Internacional, la Alianza”.

41 Véase Instituto de Historia: Historia del movimiento obrero, vol. 1, págs. 37-39; Plasencia y Moro, Aleida, comp.: Bibliografía de la Guerra de los Diez Años, La Habana, 1968, doc. 846; Poyo: "Key West...", pág. 301; Poyo, Gerald E.: "The Anarchist Challenge to the Cuban Independence Movement, 1885-1890”, Cuban Studies, vol. 15:1, Pittsburg, 1985, pág. 31; Le Riverend, Julio E.: "Cuba: La revolución de 1868 como transición ideológica”, Casa de las Américas, 84, La Habana, 1974, pág. 17.

42 Sobre las tensiones existentes en el campo separatista en relación a la estratificación racial y la esclavitud, véase Ferrer, Ada: "To Make a Free Nation: Race and the Struggle for Independence in Cuba, 1868-1898". Tesis doctoral, Universidad de Michigan, 1995, caps. 2-3; y Robert, Karen: "Slavery and Freedom in the Ten Years' War, Cuba, 1868-1878", Slavery and Abolition, 13:3, Londres, 1992, págs. 181-200. 
Rico, con la promesa de indemnizar a los propietarios de esclavos, causó el pánico en el partido español en Cuba. Asimismo, el gobierno depuso al ultraconservador capitán general Francisco Cevallos y nombró al reformista Cándido Pieltain. Al llegar a Cuba en abril, Pieltain comenzó a devolver algunos de los bienes embargados por sus predecesores desde 1869 , y concedió un cierto margen de libertad a la prensa. Inmediatamente surgieron varios periódicos republicano-federales. Los más populares eran La Legalidad, La República Española, El Tribuno, El Gorro Frigio, La Unión y El Trabajo, todos ellos publicados en La Habana. Pieltain incluso autorizó la fundación de varias asociaciones obreras de ayuda mutua, de recreo y de educación. Como era previsible los miembros del Casino Español se opusieron visceralmente a todas estas medidas reformistas, e hicieron todo lo posible por limitar la capacidad de acción del nuevo capitán general. ${ }^{43}$

La tolerancia de Pieltain permitió que varios grupos pro-españoles de ideas avanzadas - tales como los masones, los espiritistas, los republicanos federales y los activistas obreros - abandonaran la clandestinidad e iniciaran una campaña en favor de la aplicación de importantes reformas administrativas en Cuba. Todos estos grupos estaban estrechamente relacionados entre sí, circunstancia que explica las numerosas referencias masónicas contenidas en la prensa obrera impresa en la isla durante la Primera República. Además del auge de la masonería, el espiritismo comenzó a difundirse en el territorio, y en pocos años conseguiría tener gran arraigo. En marzo de 1873, el capitán general permitió el establecimiento de la Sociedad Spiritista, en La Habana. Según sus fundadores era ésta una "Sociedad científica cual las establecidas en otras épocas para estudiar los fenómenos del sonambulismo y del magnetismo animal". No obstante, al igual que en las logias masónicas partidarias del dominio español, la Sociedad Spiritista formaba parte de la red de organizaciones republicano-federales en Cuba. ${ }^{44}$

Las actividades de los republicanos federales consiguieron movilizar a un amplio sector de las clases subalternas en las poblaciones del Occidente cubano. El programa de los federales era la asimilación de Cuba a España —ello significaba que todas las leyes vigentes en la península se

43 Pieltain, Cándido: La isla de Cuba desde mediados de Abril a fines de Octubre de 1873, Madrid, 1879, págs. 107-115. Soulère, Emilio A.: Historia de la insurrección de Cuba (1869-1879), Barcelona, 1879-1880, vol. I, caps. 15-16. Roldán, Inés: "La I República en Cuba", Revista Complutense de Historia de América, 18, Madrid, 1992, págs. 257-279.

44 AHN, Ultramar, 5897; y Archivo Nacional de Cuba (en adelante, ANC), Gobierno General (en adelante, G.G.), 555, exp. 27201. 
aplicasen íntegramente allí-. ${ }^{45}$ Fue en este período que Niceto Solá y Freixas, un periodista catalán, se convirtió en una figura popular en la isla como editor del El Tribuno Español (febrero-julio de 1873) y de El Gorro Frigio (agosto-noviembre de 1873), dos de los periódicos republicanos federales de más difusión. En su defensa de la república, Solá llegó a afirmar: "El odio de muchos de los hijos de Cuba a España no es motivado por otras causas que las que motivaban el odio de los catalanes a Castilla; las libertades extinguieron aquél, las libertades extinguirán éste" ${ }^{46}$

Poco después del desembarco de Pieltain en Cuba, Niceto Solá y Enrique Hompanera, otro colaborador de El Tribuno de origen madrileño, establecieron el Centro Nacional de Artesanos. En la solicitud al gobierno general, Solá y Hompanera declaraban que eran leales "peninsulares" que deseaban "establecer en esta ciudad una institución de recreo con iguales condiciones a las sociedades El Casino español de La Habana, [y el] Recreo Social y Sociedad del Pilar" - la primera sociedad de artesanos de Cuba fundada en 1848 - A diferencia de la habitual lentitud con que se tramitaban este tipo de solicitudes, Pieltain no se lo pensó dos veces y autorizó la asociación inmediatamente.

Poco después de la fundación del Centro Nacional, el capitán general autorizó otras asociaciones vinculadas al Centro, a la vez que daba más libertad a las asociaciones populares ya existentes tales como El Pilar. Sin duda Pieltain veía en estas sociedades una forma de contrarrestar la oposición que le hacían los comerciantes, los marquistas y los hacendados del Casino Español. Como era de suponer, el Centro Nacional de Artesanos nunca fue un club de recreo o una sociedad de socorros mutuos, sino un centro republicano federal en cuya sede - el teatro Ariosa con un aforo para 800 personas - se reunían los trabajadores para intentar recomponer el movimiento obrero. Según los informes de la policía, en las reuniones que cada domingo convocaba esta sociedad, el teatro Ariosa se llenaba a rebosar. ${ }^{47}$

45 Sobre el programa de los republicanos federales en Cuba, véase "Manifiesto", La Unión, 14, La Habana, 31 de agosto de 1873, pág. 3; y AHN, Ultramar, 4736-3, exp. 69, 29 de agosto de 1873, "La Comisión republicana de la Isla de Cuba [...] solicita [...] que la provincia cubana pueda disfrutar de las mismas libertades de que gozan en la Península [...]".

46 El Trabajo, 1, La Habana, 7 de septiembre de 1873, págs. 6-7. Sobre Solá, véase Urrutia, Carlos de: Los criminales de Cuba y D. José Trujillo, Barcelona, 1882, págs. 103-104.

47 AHN, Ultramar, 5899, exp. del Casino Nacional. Otras asociaciones autorizadas por Pieltain fueron Nuestra Señora de las Mercedes y Sociedad Benéfica y de Recreo El Progreso. Véase AHN, Ultramar, 5897, 5898; ANC, GG, 89, exp. 3710; La Unión, 1, La Habana, 1 de junio de 1873, pág. 4 ; y núm. 28 , de 7 de diciembre de 1873 , pág. 3. 
Solá y Hompanera estaban vinculados al grupo de artesanos de oficios calificados que lideraba Saturnino Martínez, quien se había convertido en un fervoroso propagandista de la república federal. En realidad, el Centro Nacional partía de un proyecto expuesto en 1865 en las páginas de $L a$ Aurora de fundar una gran asociación de todos los tabaqueros de La Habana que estuviese abierta a cualquier persona de la clase trabajadora. En octubre de 1873, algunos de sus miembros, casi todos ellos tabaqueros, eligieron a Martínez presidente y a Niceto Solá vicepresidente de la sociedad. ${ }^{48}$ Además de participar en la fundación y dirección del Centro Nacional, desde mediados de este mismo año Martínez inició la publicación de un semanario republicano titulado La Unión: Semanario político de ciencias y literatura, dedicado a los artesanos. Desde las páginas de La Unión, Martínez dio a conocer el programa de una nueva organización política, el Comité Central Republicano Federal de Artesanos de La Habana, que estableció su sede en los locales del Centro Nacional de Artesanos. El Comité Central estaba conectado con los republicanos federales en la península y afirmaba tener representantes en todas las ciudades de la isla, desde Santiago de Cuba hasta Pinar del Río, e incluso en ciudades extranjeras como Nueva York. ${ }^{49}$

Al contrario que los republicanos federales, los republicanos conservadores fracasaron estrepitosamente en su intento por constituir un partido que contase con el respaldo de todos los peninsulares fueran de clase trabajadora o no. Poco después de la fundación del Centro Nacional de Artesanos, un grupo republicano de ideas conservadoras, contando con el respaldo de algunos marquistas, fundó el Casino Nacional. La prensa integrista utilizó la similitud en los nombres del Casino Nacional y el Centro Nacional para crear confusión, utilizándolos indistintamente como si fueran una misma cosa. Sin embargo, el Casino Nacional tuvo poquísimos asociados, que se reunían en el café El Louvre. ${ }^{50}$

Aparte de promover las organizaciones obreras y las cooperativas, los republicanos federales de Cuba apoyaron la extinción inmediata de la esclavitud, pese a que estaba prohibido hacer propaganda abolicionista en

48 El Trabajo, 6, La Habana, 12 de octubre de 1873, pág. 48.

49 La Unión, 14, La Habana, 31 de agosto de 1873, pág. 3.

50 Sobre la apertura del Casino Nacional, véase AHN, Ultramar, 5899, exp. sobre el Casino Nacional; El Trabajo, 6, La Habana, 12 de octubre de 1873, pág. 47; El Eco de Cuba, 1:8, La Habana, 14 de diciembre de 1873, pág. 4; y La Voz de Cuba, 232, La Habana, 1 de octubre de 1873, pág. 3; 252, de 25 de octubre de 1873, pág. 3 ; y 270, de 13 de noviembre de 1873, pág. 3. 
la isla. Tan pronto llegó Pieltain a Cuba, la prensa republicana comenzó a atacar la existencia de esa institución por su crueldad y por ser contraria a los derechos fundamentales de la humanidad. Esta campaña se intensificó a partir de junio de 1873, tras manifestar el gobierno metropolitano que la abolición de la esclavitud en Cuba era una de sus prioridades. ${ }^{51}$ El Comité Central Republicano Federal, al nombrar a Emilio Castelar presidente honorario unos meses antes de que fuese nombrado presidente de la república, puso de manifiesto tanto su republicanismo como su abolicionismo. Castelar era un destacado miembro de la Sociedad Abolicionista Española, que criticó por demasiado moderada la ley Moret promulgada en 1870, la cual liberaba a todos los hijos nacidos de una esclava después de septiembre de 1868, y a todos los esclavos mayores de sesenta años..$^{52}$

Los republicanos federales constantemente recurrían al ejemplo de la abolición en Puerto Rico para mostrar que era posible en Cuba sin ningún trastorno social. Las importantes reformas políticas introducidas por el gobierno de la República en aquella isla, y la popularidad alcanzada por los republicanos federales puertorriqueños con su apoyo a la organización de los trabajadores, alentaron a homónimos cubanos a promover la extensión de estas reformas a la Gran Antilla. ${ }^{53}$ Así vemos como ya en su primer número, el semanario El Trabajo publicó un artículo de Ángel Claveles, un integrante del Comité Central Republicano Federal de La Habana, en el que se defendía la abolición de la esclavitud en Cuba basándose en el modelo puertorriqueño: "Tres veces han pedido los porto-riqueños la abolición inmediata e indemnizada. Una en el seno de la Junta de información de 1867 , y las dos restantes en las Cortes de 1870 y 1871 . Hoy el problema está resuelto según sus deseos, sin que las catástrofes y las conmociones que se temían, hayan tenido lugar". Según Claveles, una vez emancipados los esclavos, en lugar de pensar en vengarse, se olvidarían del pasado y trabajarían en la construcción del futuro. ${ }^{54}$

51 Véase La Unión, agosto-octubre de 1873.

52 Posteriormente, como presidente de la República, Castelar reprimió violentamente los levantamientos cantonalistas y eludió cualquier referencia a la abolición de la esclavitud en Cuba. Sobre el abolicionismo de Castelar, véase su artículo "La abolición de la esclavitud", 8 de junio de 1865, publicado en Cuestiones políticas y sociales, Madrid, 1870, vol. 3, págs. 83-91; y su Discurso pronunciado [...] en la sesión de 20 de junio de 1870, Madrid, 1870.

53 Sobre los republicanos federales en Puerto Rico en 1873, véase García, Gervasio Luis, y Quintero Rivera, A.G.: Desafío y solidaridad: breve historia del movimiento obrero puertorriqueño, Río Piedras, 1982, págs. 18-29.

54 Claveles, Ángel: "Un poco de todo", El Trabajo, 1, La Habana, 7 de septiembre de 1873, págs. 6-7. 
El Trabajo, además, publicó que en la fábrica Partagás, en la que Martínez trabajaba como capataz, los trabajadores habían realizado una colecta para manumitir a "varios siervos". En otro artículo, El Trabajo informó que los trabajadores de esa misma fábrica pagaron la cuota de la carta de libertad de un esclavo cuya dueña había decidido liberarlo después de leer una editorial del semanario obrero La Unión, sin duda el principal órgano del abolicionismo en Cuba. ${ }^{55}$ Propagar este modo de manumisión, aunque muy moderado, era una de los pocos recursos de que disponía el movimiento obrero para expresar su deseo "de ver desaparecer la fatal esclavitud". ${ }^{56}$ Este abolicionismo, no obstante, no significaba ausencia de racismo. Siguiendo al ideario reformista, siempre tan preocupado por el blanqueamiento de la isla, un artículo editorial de La Unión, contrario a la entrada de trabajadores asiáticos sujetos a contrata, manifestaba que Cuba debía aumentar su población, pero que ésta debía ser de "raza blanca o europea". ${ }^{57}$

La popularidad de los republicanos federales entre la clase artesana contribuyó a limitar la influencia que la prensa integrista y los casinos españoles ejercían sobre los trabajadores y la tropa de los batallones de voluntarios. El Trabajo, mucho más cercano que La Unión a las posturas pro-criollas, llegó a sugerir que los cubanos no eran un pueblo libre ${ }^{58}$ Para contrarrestar el avance republicano, el partido español lanzó una venenosa campaña en que acusó a los federalistas de defender peligrosas ideas

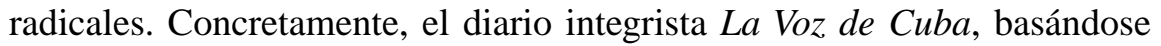
en un artículo publicado por La Nación - un periódico separatista impreso en la ciudad de México - insinuó que Saturnino Martínez era el "Presidente de la Internacional en toda la isla de Cuba". Como era de suponer, Martínez lo negó rotundamente, en tanto que El Trabajo declaraba que si hubiese sido cierto el nombramiento de aquél como delegado de La Internacional, él no hubiera tenido "empacho en manifestarlo así, porque después de todo, la Internacional de obreros no es lo que aquí se pretende hacer creer por los encubiertos enemigos del gobierno y de la Repú-

55 El Trabajo, 10, La Habana, 9 de noviembre de 1873, pág. 78; 8, de 26 de octubre del mismo año, pág. 64.

56 J. de J. Márquez: "Esclavos", La Unión, 11, La Habana, 10 de agosto de 1873, págs. 2-3. Sobre el desarrollo del abolicionismo popular en Cuba, véase Casanovas, Joan: "Slavery, the Labour Movement and Spanish Colonialism in Cuba (1850-1890)", International Review of Social History, 40:3, Cambridge, 1995, págs. 367-382.

57 "Inmigración Asiática”, La Unión, 20, La Habana, 12 de octubre de 1873, pág. 2.

58 El Trabajo, 8, La Habana, 26 de octubre de 1873, pág. 64. 
blica". ${ }^{99}$ En otros artículos, El Trabajo manifestó sus simpatías por organizaciones como el Gran Círculo de Obreros, fundado en 1870 en la ciudad de México por algunos anarquistas que estaban al corriente del movimiento obrero internacional. ${ }^{60}$

A medida que la polémica subía de tono, la prensa integrista afirmó que los republicanos federales carecían de fervor patriótico, e incluso que pertenecían al ala más radical del independentismo, los seguidores de Carlos Manuel de Céspedes. ${ }^{61}$ Paralelamente a esta polémica, y en contra de la voluntad de Pieltain, el partido español comenzó a expulsar a los republicanos federales del cuerpo de voluntarios..$^{62}$ Como respuesta a las maniobras integristas, El Trabajo manifestó que "la inmensa mayoría de voluntarios" eran artesanos, quienes, "para cubrir una guardia han tenido que sacrificar su trabajo y su comodidad en aras del bien común, mientras algunos prohombres a la sombra de la bandera nacional y cubiertos con el manto de un patriotismo fingido, han amontonado inmensos capitales que quizá sirven hoy para hacer cruda guerra a las instituciones patrias". ${ }^{63}$ Según El Trabajo, los voluntarios no pertenecían, como tales, "a ningún partido político", sino "a la nación española", y por esta razón no podían estar sujetos "a la opinión de ningún jefe". Por otra parte, la libertad de que disfrutaban como ciudadanos leales a la República estimulaba su "amor a la patria". ${ }^{64}$

La presión que el partido español ejerció sobre la administración colonial fue tal, que logró que el gobierno relevara a Pieltain y entregara el mando de la isla al intransigente general Joaquín Jovellar. A su llegada a comienzos de noviembre, Jovellar se puso incondicionalmente del lado del partido español y, atendiendo a las insidiosas acusaciones de $L a \mathrm{Voz}$, impuso de nuevo una estricta censura de prensa a todos los periódicos que no

59 "El Jefe de la Internacional”, La Voz de Cuba, 233, La Habana, 2 de octubre de 1873, pág. 2. Carta de Saturnino Martínez al editor, Ibídem, 235, de 4 de octubre de 1873, pág. 2. El Trabajo, 6, La Habana, 12 de octubre de 1873, pág. 48. Según El Trabajo, 7, de 19 del mismo mes y año, pág. 56, el director de La Nación era Francisco Socarrás Wilson, quien antes de la guerra fundó y dirigió la publicación reformista El Camagüey.

60 "Círculo de obreros", El Trabajo, 7, La Habana, 19 de octubre de 1873, pág. 54. Sobre la fundación del Gran Círculo, véase Hart, John M.: Anarchism \& the Mexican Working Class, 1860-1931, Austin, 1987, págs. 43-59.

61 La Unión, 10, La Habana, 3 de agosto de 1873, pág. 1; El Trabajo, 2, La Habana, 14 de septiembre de 1873, págs. 15-16. Sobre la polémica con la prensa integrista, véase los números de La Voz de Cuba publicados durante este período, y Pieltain: La isla de..., págs. 112-113.

62 El Trabajo, 4, La Habana, 28 de septiembre de 1873, pág. 29.

63 "Calumnias", Ibídem, 7, de 19 de octubre de 1873, págs. 53-54.

64 Ibídem, 4, de 28 de septiembre de 1873, pág. 29. 
fueran integristas. ${ }^{65}$ Para justificar su decisión, el capitán general telegrafió a Madrid: "Las clases superiores están sometidas, cosa que no ocurre con las inferiores". ${ }^{66}$

Pese a la política de Jovellar, en diciembre de 1873 el Centro Nacional sirvió de plataforma desde la que se coordinó la petición de un aumento de jornal en varias fábricas de tabacos. Aunque entre 1870 y 1874 las exportaciones de azúcar y tabaco aumentaron, desde 1869 el Banco Español de L Habana comenzó a imprimir grandes cantidades de moneda fiduciaria para financiar la guerra. Por ello, en muy poco tiempo la moneda en metálico dejó de circular, mientras que los billetes no dejaban de perder valor, hecho que unido a la escasez de alimentos debida a la guerra, provocó una fuerte subida de los precios de los productos básicos de consumo. ${ }^{67}$ La proclamación de la República y el miedo de la elite insular a la abolición de la esclavitud ocasionaron la caída libre del peso en billete, que a fines de 1873 sólo valía el $55 \%$ del peso en oro. La inestabilidad monetaria era tal, que hacia finales de 1873 bastantes fábricas de tabacos cerraron o redujeron el número de trabajadores que empleaban, generándose así una ola de desempleo. ${ }^{68}$

Al igual que en la huelga de los tabaqueros de La Habana de septiembre de 1867, Saturnino Martínez fue uno de los principales dirigentes del conflicto obrero que se desarrolló entre finales de diciembre de 1873 y comienzos de enero de 1874. La policía informó al gobierno de la isla que en una asamblea de trabajadores en el teatro Ariosa, entre setecientas y ochocientas personas habían elegido como delegado a aquel dirigente, quien propuso ante todos la formación de "Comisiones para pasar a todas las fábricas donde trabajan operarios para exigir a los dueños el aumento del tanto por ciento a los salarios de los mismos". En caso de que los patrones "no estuviesen conformes", las comisiones debían dar cuenta al Centro Nacional, el cual — según la policía - apoyaría a los trabajadores que se declarasen en huelga. ${ }^{69}$ Paralelamente a las reivindicaciones de los tabaqueros, los "cargadores del muelle, los carretoneros y cocheros" - por

65 La Voz de Cuba, 264, de 6 de noviembre de 1873, pág. 2; y 267, de 9 de noviembre de 1873, pág. 2.

66 RAH, Colección Caballero de Rodas, vol. V, doc. 1213, fol. 247v., telegrama de Jovellar al presidente del Gobierno, Castelar, 18 de noviembre de 1873.

67 Sobre la inestabilidad monetaria durante la guerra, véase Roldán: La hacienda..., págs. 31-36, 88-106.

68 "Cuestion de trabajo", La Unión, 28, de 7 de diciembre de 1873, pág. 3. El Trabajo, 15, de 14 de diciembre de 1873, pág. 120 .

69 AHN, Ultramar, 5899, exp. sobre el Centro Nacional; y La Voz de Cuba, 5, La Habana, 6 de enero de 1874, pág. 3. 
aquellos años ya mayoritariamente peninsulares - amenazaban con una huelga general..$^{70}$

En estos mismos días, el general Manuel Pavía entraba con sus tropas en el Congreso en Madrid y ponía fin a la República. Inmediatamente, el gobierno provisional obligó a las organizaciones de trabajadores a actuar en la más absoluta clandestinidad. Entonces, contando con el apoyo del partido español, Jovellar puso fin al movimiento obrero republicano federal. A finales de enero cerró el Centro Nacional y suspendió definitivamente La Unión y El Trabajo, así como a varios periódicos masónicos y espiritistas. ${ }^{71}$ Por otra parte, comenzó a reestructurar las fuerzas militares. En una de sus primeras disposiciones, ordenó la movilización a las zonas de guerra del $10 \%$ de la tropa de los voluntarios. ${ }^{72}$ A raíz de la medida, varios centenares de trabajadores peninsulares se manifestaron frente al palacio del capitán general para "pedirle que mandase a campaña los cuerpos de voluntarios enteros con sus respectivos oficiales", en lugar de sólo a la tropa. Para dispersar a los voluntarios, Jovellar tuvo que recurrir a la Guardia Civil. Como consecuencia de la manifestación, Saturnino Martínez fue arrestado y deportado a la península. Solá, por su parte, consiguió eludir la persecución policial durante algún tiempo hasta ser arrestado y encarcelado, en tanto que Enrique Hompanera, un coeditor de El Tribuno, fue encarcelado a mediados de 1874 y murió poco después de quedar en libertad. ${ }^{73}$ A pesar de la represión, el movimiento obrero republicano federal no desapareció por completo, simplemente tuvo que refugiarse en la clandestinidad por espacio de dos años. Al ir asentándose el nuevo régimen de la Restauración, y sobretodo con la llegada a Cuba del reformista general Martínez Campos a finales de 1876, el asociacionismo popular comenzó a recuperarse, de modo que al finalizar la guerra en 1878, el movimiento obrero cubano no tuvo mayor dificultad en expandirse enormemente en muy poco tiempo. ${ }^{74}$

\footnotetext{
70 Soulère: Historia..., vol. 1, pág. 686.

71 Gutiérrez de la Concha, José: Memoria sobre la Guerra de la Isla de Cuba, Madrid, 1875, pág. 109.

72 RAH, Colección Caballero de Rodas, vol. V, doc. 1332, fol. 382v, "Telegrama del GSC al ministro de la Guerra", 1 de marzo de 1874.

73 Soulère: Historia..., vol. 1, pág. 688. Urrutia: Los criminales..., págs. 103-104. Giralt: Historia..., pág. 35 .

74 Sobre esta súbita expansión del movimiento obrero, véanse Casanovas, Joan: "El asociacionismo burgués y proletario en Cuba de 1868 a inicios de los años 1880”, en Josef Opatrný, ed.: Cuba: algunos problemas de su historia, Praga, 1995, págs. 97-115, y "El movimiento obrero cubano del reformismo al anarquismo", Historia y Sociedad (Puerto Rico, en prensa).
} 


\section{Conclusión}

La Guerra de los Diez Años puso de relieve las fuertes divisiones existentes dentro de las clases subalternas urbanas, basadas en diferencias de origen (peninsular-criollo) o de color (blancos-no blancos). Aunque la mayoría de trabajadores urbanos no abandonaron la isla a raíz de la guerra, la intensificación de la represión gubernamental significó la casi completa desaparición del movimiento obrero. De todos modos, poco a poco, y bajo el liderazgo de trabajadores peninsulares, dicho movimiento fue recomponiéndose dentro de la isla. Paralelamente, los trabajadores criollos exiliados aprovecharon la mayor libertad que gozaban en Estados Unidos para fundar sus propias organizaciones vinculadas al movimiento independentista. Aunque estas dos ramas del movimiento obrero cubano habían participado conjuntamente en las luchas del obrerismo reformista de mediados de 1860, la guerra las aisló de tal manera que cada una de ellas siguió su propio camino hasta el fin de la Guerra.

La evolución de estas dos ramas del movimiento obrero muestra que a pesar de estar subordinadas a los líderes del partido español y del movimiento separatista respectivamente, ambas procuraron desarrollar formas de organización y lucha obrera autónomas. En el interior de la isla, los trabajadores urbanos lucharon tenazmente por reconstruir el movimiento obrero y cada vez más expresaron su disconformidad con los peninsulares adinerados que dirigían el partido español. Fue durante la Primera República cuando se observan más claramente las fuertes fricciones existentes entre estas dos clases sociales. Por su parte, los trabajadores de la emigración expresaron su disconformidad con el sector más conservador del movimiento independentista — dirigido por Miguel Aldama-, apoyando al más progresista — dirigido por Manuel de Quesada - En su conjunto, las asociaciones que fundaron estas dos ramas del movimiento obrero cubano pusieron los cimientos que permitirían su fuerte expansión después de finalizada la guerra. 